\title{
LAS INSIGNIAS DE CORONACIÓN DE PEDRO I-II "EL CATÓLICO", DEPOSITADAS EN EL MONASTERIO DE SIJENA
}

\author{
RaFAel Conde y Delgado DE Molina \\ Archivo de la Corona de Aragón \\ (Barcelona)
}

En el monasterio de Sijena' ${ }^{1}$, fundado por Sancha de Castilla, esposa de Alfonso el Trovador bajo regla de San Juan de Jerusalén, constituyó Jaime I un importante depósito archivístico en el que se conservaban documentos de tanto peso para la corona como los relativos a la conquista de Mallorca y Valencia, a las relaciones con Castilla y Navarra, y a la administración de los territorios ultrapirenaicos ${ }^{2}$. El depósito duró hasta el año 1308 fecha en que Jaime II pidió su devolución a la entonces priora Teresa Jiménez de Urrea ${ }^{3}$.

\footnotetext{
'Sobre el monasterio de Sijena, cf. Agustín Ubieto ArTETA, Documentos de Sijena. I. Valencia, 1972; y Regina SÁINZ DE LA MAZA, El Monasterio de Sijena. Catálogo de documentos del Archivo de la Corona de Aragón (1208-1348), Barcelona, 1994, como obras documentales más recientes.

"Cf. Rafael CONDE y Delgado de Molina, Los Archivos Reales o la memoria del poder. En "XV Congreso de Historia de la Corona de Aragón (1993). Actas", I, Zaragoza, 1996, pp. 121-139, y Las primeras Ordenanzas del Archivo Real de Barcelona. 1384, Madrid, 1993, pp. 6-8. Con anterioridad al depósito constituído por Jaime I, custodiaba ya el monasterio documentación ajena a su institución. En abril de 1217, por ejemplo, la priora Ozenda acusa recibo de la comanda de cuatro importantes documentos de la dote de Constanza, hija de Alfonso el Trovador, reina de Sicilia como esposa en segundas nupcias de Federico II (en primeras lo fue del rey de Hungría), de dos privilegios papales y de un documento de Gomita Pagano. Documentos, pues, ligados, como el propio monasterio, a la familia real.

${ }^{3}$ ACA. Canc. reg. 140, fol. 88 r". J. MIRET I SANS, Les cases de Templers y Hospitalers en Catalunya. Barcelona, 1910, pág. 417, y Regina SÁINZ DE LA MAZA, El Monasterio de Sijena, cit. doc. 259 , pág. 88

"Anuario de l:studios Medievales". 28 (1998)
} 
Sijena custodiaba. por otra parte, las insignias de la coronación que Pedro el Católico había recibido del papa Inocencio III cuando fue solemnemente coronado en Roma en 1204.

Según el testimonio que de la misma quedó en los registros vaticanos, Pedro fue coronado en el monasterio de San Pancracio de Roma por del propio papa, largiens ei regalia insignia universa por mano de Pedro, cardenal de Ostia ${ }^{4}$. Se pregunta Schramm es su estudio sobre las insignias del poder en el medievo español ${ }^{5}$ si se las regaló o llevó Pedro al menos la corona, interpretando tal vez el largiens como simple entrega ${ }^{6}$. De un texto alternativo recogido por Du Cange ${ }^{7}$ se deduce que, efectivamente, las insignias fueron regalo del papa como gracia especial: "regalia insignia universa, mantum videlicet et colobium, sceptrum et pomum, coronam et mitram ad opus tuum non miunus preciosa quam speciosa fecimus preparari, et ea liberaliter tibi donavimus in signum gratiae spaecialis (...)"

De acuerdo con el Ordo, fueron entregados a Pedro, vestiduras, tocados y objetos.

En cuanto a las primeras, el texto precisa mantum y colobium. Si la palabra mantum es facilmente comprensible, no ocurre lo mismo con colobium. No ocurre lo mismo hasta el punto de que Zurita, en el relato de la ceremonia, se hace eco de la entrega de vestuario etc, y, refieriéndose sin duda al colobium, afirma que "algunas de ellas apenas se entienden"

Según Du Cange, el término tiene tres acepciones: "tunica absque manicis, vel certe cum manicis sed brevioribus et quae ad cubitum vix pertinerent [...] Postmodum propria fuit vestem monacorum [...]. Etiam fuit episcoporum vestis propria". Y continua: "Colobium erat cucullata vestis sine manicis, sicut adhuc videmus in monachorum cucullis, vel nautarum

\footnotetext{
${ }^{4}$ Ordo coronationis Petri regis Aragonum. 1204 noviembre 10. Roma. Reg. Vaticano 5, fols. 202-202v. Ultimamente Bonifacio PALACIOS MARTín, La coronación de los reyes de Aragón, Valencia, 1975, Apéndice Documental, doc. II.

${ }^{5}$ Las insignias de la realeza en la Edad Media española. Traducción y prólogo de Luis Vazquez de Parga, Madrid, 1960

"“fué el propio papa quien colocó al Rey la corona, sin que sepamos si éste la llevó consigo o si el Papa le prestó una para la ceremonia" (pp. 91-92).

${ }^{7}$ Glossarium ad scriptores mediae et infimat latinitatis, auctore Carolo Dufresne, domino du Cange, regii a consiliis et franciae apud ambianos quaestore. Editio nova locupletior et auctior (...) Parisiis, sub oliva Caroli Osmom, via San-jacobaea, MDCCXXXIV. s.v. Mitra

${ }^{8}$ Libro II, cap. LI: "Que el rey fue con su armada a Roma adonde le corono el Papa Innocencio, y constituyo por esto su reyno censatario a la Iglesia".
} 
tunicis, quod colobium a Sancto Silvestro in Dalmaticam est versum, et additis manicis infra sacrificum portari instituta quae adeo ad Missam a Pontifice portatur".

Todas estas interpretaciones remiten a una túnica. Con ellas se muestra de acuerdo, p.e. Antonio Lopez Ferreiro, en sus Lecciones de Arqueología Sagrada, donde da el colobium como antecedente inmediato de la dalmática ${ }^{9}$. Antonio Durán Gudiol, en cambio, hace sinónimo colobium de "esclavina", y la hace equuivalente a la marina purpura auro decora que aparece en el Pontifical de Huesca posterior ${ }^{10}$, significado que se aproxima a otro, absoluitamente marginal, recogido tambien por Du Cange: "Colobium dicitur etiam cucullus ille, sive superhumerale, quo induuntur servientes ad legem in Anglia". El entorno eclesiático en que se encuentra el término, me lleva a aceptar la primera interpretación, pese a que, en nuestro documento aparece por dos veces cancelada la palabra amitum, que remite a esta significación de colobium por ser vestidura suprahumeral.

De esta única vestidura específica, se pasa progresivamente a un complejo vestuario, que encuentra su punto culminante en el minucioso y puntillista Pedro el Ceremonioso. El manto desaparece ya en el pontifical de Huesca mientras se introduce la marina purpura auro decora y el amphiballum $^{11}$ o casulla, blanca. En las coronaciones de Alfonso III-IV y Pedro III-IV se mantiene la dalmática - en el ceremonial de Pedro III-IV "de vellut vermell e de drap d'or de nostres senyal reyal" - y se añade la estola, llevada al modo diaconal, y el manípulo.

Por lo que a tocado se refiere, Pedro recibió dos: la mitra y la corona real. La mitra era tocado presente en las coronaciones imperiales. Du Cange lo recoge: "Mitram denique vocabant nostri capitis tegumentum, quod Imperatorum et regum coronis substernitur. Ceremoniale romanum lib. I, sect. 5 ubi corona Imperatoris describitur: Differt forma coronae Imperialis ab aliis: nam ea sub se thiaram quandam habet in modum fere Episcopalis Mitrae, humiliorem tamen, magis apertam et minus acutam; estque eius apertura a fronte, non ab aure".

\footnotetext{
${ }^{9}$ Segunda edición, Santiago 1894, pp. 413-416.

${ }^{10}$ El rito de coronación del rey de Aragón, en "Argensola", 103 (1989) pp. 18 y 23.

" "Casula, indumentum sacerdotale (...) Casula, quam amphiballum vocant, quod sacerdos induetur, tota unita per Moysem legiferum instituta primitus demostatur". DU CANGE, Glossarium cit., s.v amphiballum.
} 
La corona es, por su valor simbólico, junto con la mitra imperial el tocado más importante. Según Schramm: "una noticia ${ }^{12}$ que la investigación moderna rechaza casi siempre, nos dice que (Ramiro I) fué ungido y que el papa Benedicto IX (1033-1045) bendijo su corona y cetro"'13. En principio quien no llegó a titularse claramente rey de Aragón, sino, como mucho rey en Aragón, y Sancionis regis filius y otras formulas ambiguas, es difícil que asumiera corona y cetro. Cierto es que en algunas representaciones, concretamente en tres de los cuatro ejemplares de las llamadas "Actas del concilio de Jaca" de 1063 aparece representado Ramiro con corona y cetro, pero son todas copias o falsificaciones de mediados del XII, al igual que la donación de catorce iglesias a la catedral de Jaca, del mismo año y conservado en "copia” de la misma época ${ }^{14}$.

De esta posible corona de Ramiro, se pierde la pista. Según Schramm, que constata que no aparece en el inventario de bienes de Ramiro, "la transmisión a su hijo, hubo, pues, de ser objeto de una regulación particular" 15 .

Titulándose Ramon Berenguer IV sólo princeps de Aragón "no debió llevar corona" 16 . En efecto, los condes de Barcelona, en el llamado "Rollo genealógico de Poblet", llevan simple banda como tocado, si bien, en algun momento, la de Ramón Berenguer IV llevó florones, que hoy aparecen raspados; sería interesante saber cuando y quién se dió cuenta de que Ramon Berenguer IV no podía llevarlos. De hecho, en la reinterpretación ochocentista del "rollo", Ramon Berenguer IV lleva el mismo tocado que sus antecesores condes. Alfonso el Trovador, como rey que era, sí es representa-

\footnotetext{
${ }^{12}$ La recoge, tal vez por primera vez, el cronista aragonés Gauberto Fabricio de VAGAD en su Corónica de Aragón, impresa en Zaragoza en 1499 (Reedición facsímil con introducción a cargo de María del Carmen OrCÁSTEGUI Gros, Zaragoza, 1996), fol. XXVI v., donde de Ramiro dice: "Tomo su ilustre principio el rey primero de Aragon y deçimo de Sobrarbre con tan alto y venturoso favor, que fasta por el sancto padre Benito el octavo le fueron embiadas con solempnes mensageros las insignias reales que son el ceptro y la corona", destacando, en su fervor nacionalista, que "en las reales isignias tomo ventaja a todos los reyes de aquellos tiempos". Recoge también Vagad la especie de que Pedro el Católico "escogio de ser coronado, mas no de corona de oro y de ricas piedras preciosas, mas de mies" (fol. LXVII), de donde viene la leyenda de que fue coronado con corona de miga de pan.

${ }^{13}$ Op. cit., p. 89.

${ }^{14}$ Sobre los ejemplares conservados en el Museo Diocesano de Jaca, cf. María del Carmen LaCARra DuCay, Catedral y Museo Diocesano de Jaca, Zaragoza, 1993, pp. 70-75.

${ }^{15}$ Op. cit., pp. 89-90.

${ }^{16}$ Op. cit., p. 90.
} 
do con corona en iconografía coetánea: concretamente en las monedas acuñadas en Provenza aparece de perfil, con corona alta de tipo triangu$\operatorname{lar}^{17}$, y en los sellos, de frente, con corona claramente puntiaguda ${ }^{18}$.

Respecto a la corona de Pedro, en los sellos, la fuente iconográfica en que mejor se advierten detalles de la misma, aparece de forma constante una muy característica: una banda circular rematada por tres picos: el central rematado en cruz, y los laterales, parece, por una flor de lis. Así se ve en las bulas de plomo y alguno de los sellos de cera recogidos por Sagarra ${ }^{19}$. En las monedas, de factura siempre más tosca, aparecen dos tipos de corona: una del tipo "triangular", en las monedas acuñadas en Provenza, y otra en forma de banda con gemas incrustadas, tal vez triangular y con remates globulares, en las acuñadas en Aragón ${ }^{20}$. De todos modos el valor iconográfico de estos testimonios, por repetir estereotipos, en practicamente nulo.

De la corona de Pedro el Católico, nunca más se supo. Y al respecto hay que recordar la admiración de Schramm ante el hecho de que Jaime II no sólo estuviera dispuesto a vender su corona, sino que recomendara al rey de Francia su adquisición ${ }^{21}$ : "No puede sorprender tal presente a una iglesia [...]. Pero el caso que acabamos de citar presupone una extraña indiferencia hacia la corona. Se puede intentar atenuarla suponiendo que Jaime II [...] tenía entonces más de una corona; pero siempre quedará en pie el hecho de que el Rey, no solo no tiene escrúpulos de que su corona pase a poder del reino vecino, sino que aconseja en este sentido. Debemos sacar la consecuencia de que se sentía tan seguro de su trono, que la enajenación de sus insignias de soberanía no le producía ninguna preocupación". Cierto, pues no hubo sacralización de la corona. Las coronas se hacen y se deshacen y con harta frecuencia son objeto de empeño por el rey, siempre agobiado por estrecheces de numerario.

Esta debió ser la suerte de la corona de Pedro. Cuando Jaime I acude a Lyon con la intención de coronarse sin tener que pagar a la Santa Sede el tributo acordado por su padre, dice el Libre dels Feyts que la corona que

\footnotetext{
${ }^{17}$ M. CRUSAFONT I SABATER, Numismàtica de la Corona Catalano-aragonesa medieval (7851516), Madrid, 1982.

${ }^{18}$ Ferran de SAGARRA, Sigil-lografia Catalana, I, Barcelona, 1915, láms. VI, VII y VIII.

${ }^{19} \mathrm{Cf}$. sobre todo los sellos 11,13 y 14 de las láminas XI y XII.

${ }^{20} \mathrm{M}$. Crusafont, Op. cit., monedas 147 y 148.

${ }^{21}$ Op. cit., pp. 96-98.
} 
llevó "no en trobaria hom tan bona en Lió con aquella, car era feita ab aur et ab peres precioses que valia pus de cent mil.lia sous de torneses"22. Desde luego, no era la de Pedro el Católico.

Respecto a los objetos, recibió Pedro el cetro y el pomo; el cetro, símbolo del poder real, presente ya en la iconografía real como hemos visto, y el pomo, al que se concede simbología imperial. Precisamente tanto Schramm ${ }^{23}$ como Palacios ${ }^{24}$ coinciden en destacar que la concesión del pomo por parte del papa, junto con la mitra, fue un acto consciente de Inocencio III para restar al emperador el monopolio de tales símbolos. El anillo, insignia frecuente en los rituales de coronación, sólo aparece en el Pontifical de Huesca, y queda en el de Pedro el Ceremonioso relegado a la coronación de la reina.

Inmediatamente la iconografía de Pedro incopora cetro y pomo. El sello real anterior a la coronación presenta, reverso con el rey a caballo a parte, al rey sentado en trono con una flor de lis en la izquierda, como su padre, y con la espada en la derecha. Los sellos conservados posteriores a 1204 , en cera o en plomo, lo presentan todos ellos empuñando el cetro. Pedro deja reposar la espada sobre sus rodillas y en su lugar empuña con la derecha un largo cetro, repitiendo la posición de la espada en el más antiguo, es decir, blandiéndolo, de 1206, y vertical, asido por su mitad, a partir de de 1207. Tanto en los sellos de cera como en las bulas de plomo, el cetro aparece rematado por flor de lis. El cetro sustituye a la espada anterior y, excepto en los sellos de Jaime I, en que es siempre representado empuñando la espada ${ }^{25}$, será omnipresente en las representaciones mayestáticas de los anversos de los sellos.

Incorpora tambien el pomo, que sustituye a la flor de lis de Alfonso. El pomo pasará también a formar parte de la iconografía habitual, incluso en el caso de Jaime I que no llegó a coronarse. Es siempre globular,

\footnotetext{
${ }^{22}$ Crònica o Llibre dels feits, Barcelona, Edicions 62, 1982, a cargo de Ferran SoldEVILA, caps. 536-538.

${ }^{23}$ Las insignias, cit., p. 129.

${ }^{24}$ Imágenes y simbolos del poder real en la Corona de Aragón. En "Actas del $\mathrm{XV}^{\circ} \mathrm{Congreso}$ de Historia de la Corona de Aragón", Jaca, 1993. Tomo I, vol 1 ${ }^{\circ}$, Crónica.

${ }^{25}$ Sobre la importancia de la espada en la España medieval cf. SCHRAMM, Las Insignias, cit. pag. 57 y 62 y B. PALACIOS, La coronación, cit. pp. 81-88
} 
naturalmente, y rematado por una cruz simple en las representaciones del $\mathbf{s}$. XIII y por cruz doble a partir de Jaime II. Siempre en la mano izquierda ${ }^{26}$.

Cetro, corona, pomo y mitra quedaron depositadas, en fecha no precisada, en Sijena, sin duda debido a la vinculación del monasterio a la familia real. En el documento de Sijena la priora Ozenda se compromete a entregar todo ello a requerimiento de Jaime en vida suya, desentendiéndose, curiosamente, del depósito a su muerte: "scilicet in diebus vestris, quod nos reddamus vobis et post dies vestros non teneamini alicui respondere de rebus predictis unquam nec de aliquo eciam racione vestri aliquo modo".

El documento disipa las dudas que planteó Schramm sobre el destino de estas insignias: "No cabe duda de que Pedro volvió con esa corona a su pais, pues de lo contrario se advertiría en el programa protocolario, en que se basa nuestro conocimiento de esta ceremonia, que no se trataba sólo de un gesto simbólico-jurídico del Rey, sino de la donación a la Iglesia"27.

Jaime I no llegó a coronarse. En 1229 hubo un primer intento, que fracasó. Volvió a intentarlo en 1274. Jaime acudió a Lyon, ante Gregorio XI con la corona bajo el brazo. Mucho se ha escrito sobre el contenido o significación política de la negativa del rey a someterse a las pretensiones papales. Pero, en realidad, si damos crédito al Llibre dels Feyts, lo que molesta a Jaime no son tanto éstas, como el que se le reclame el censo atrasado. Jaime se presenta con el prestigio de haber arrebatado dos reinos al Islam y se tropieza con la ciatería curial.

El documento fue publicado por Sanpere y Miquel $^{28}$ con lagunas, las mismas que aparecen en las llamadas "transcripciones de Bofarull" existentes en el Archivo de la Corona de Aragón. Ha sido reeditado por Agustín Ubieto con algunas de dichas lagunas colmadas intuitivamente ${ }^{29}$. Una atenta lectura y la utilización de técnicas inexistentes en el siglo anterior, permiten un lectura integral del mismo.

Sanpere y Miquel sugiere un error en la fecha basándose en la existencia de otro documento, que no cita, fechado en Tarragona el mismo dia. Miret i Sans, no obstante, en su itinerario de Jaime I no halla inconve-

\footnotetext{
${ }^{26} \mathrm{Cf}$. SAGarra, Op. cit., sellos 6-30, láms. VIII-XVIII.

${ }^{27}$ Op. cit. p. 92.

${ }^{28}$ En Minoría de Jaime I, en "[I] Congreso de Historia de la Corona de Aragón", II, Barcelona, 1913, p. 667.

${ }^{29}$ Documentos de Sijena, I, cit., doc. 84, pp. 133-134.
} 
niente alguno en la fecha, dado que el documento fechado en Tarragona, que ha de ser el de concesión de protección a la iglesia de Tarragona, se conserva en una copia en el Llibre de la corretja del Archivo Diocesano de Tarragona, pero también en una copia registral en el $\mathrm{ACA}^{30}$ que da fecha de kalendas de julio y no de junio. Miret i Sans concede más autoridad a esta copia que a la tarraconense, y no plantea dudas sobre la datación.

Lo citan, entre otros, Miret y Sans en su itinerario del Conquistador $^{31}$. Ultimamente ha sido regestado por Regina Sainz de la Maza ${ }^{32}$. No lo cita Huici.

Sanpere i Miquel lo coloca en el viaje que desde Zaragoza hizo a Tarragona Jaime I en estas fechas, desde el "secuestro" del rey, cuya autenticidad discute ampliamente, hacia las cortes de Tarragona de junio de este año cuya realidad niega. Sanpere declara que "no se comprende qué necesidad tenía Jaime de la declaración de la Priora de Sijena (...) ni que esta petición no la hicieran Jaime y sus consejeros o el Maestre del Temple, bien que el camarero de Monzón la autoriza" ${ }^{33}$. Recordemos que el documento se produce en un momento de fuerte tensión política interna. ¿No podría responder a un amago de una de las facciones en guerra de "patrocinar" la coronación y beneficiarse así del ascendiente adquirido?

${ }^{30} \mathrm{ACA}$, Cancillería, registro 3, Rescripta et instrumenta super Tarrachone et Campum, fols 30r. $-31 \mathrm{r}$

${ }^{31}$ pp. 26-27.

${ }^{32}$ Op. cit. doc. 3.

${ }^{33}$ Op. cit., p. 667. 


\section{DOCUMENTO}

1218 junio 1.

Ozenda, priora del monasterio de Sijena, se compromete a entregar a Jaime I, cuando quiera coronarse, la corona y las otras insignias reales de Pedro I-II el Católico.

ACA, Canc. perg. Jaime I, $\mathrm{n}^{\circ}$ 108. Sig. ant. 17 Armari de Aragó, sach B. $n^{\circ} 288$.

Perg. $147 \times$ 90. Partido por lado izquierdo, por A...F

In Christi nomine. Sit notum cunctis hoc audientibus quod nos domna Cenda, Dei gracia humilis priorissa de Sixena cum volumtate omnis conventus eiusdem domus dominarum videlicet et fratrum, concedimus et convenimus vobis Iacobo regi Aragonum et comiti Barchinone et domino Montispesulani, ut quacumque hora vos queritis vobis coronam et mitram et sceptrum ${ }^{\mathrm{a}}$ et pomum similiter $^{b}$ que fuerunt honorabilis patris vestri Petri regis Aragonum et comitis Barchinone cui eterna sit requies, scilicet in diebus vestris quod nos reddamus vobis, et post dies vestros non teneamini alicui respondere de rebus predictis unquam nec de aliquo eciam racione vestri aliquo modo.

Actum est hoc calendas iunii anno Christi $\mathrm{M} \mathrm{CCXVIII}^{\circ}$, in presencia et in posse fratris Petri, preceptoris de Sixena, et fratris Petri Sancii presbiteri priorisse de Sixena, et fratris R. de Almis camerarii castri Monsonis, et fratris Guillelmi Fulchonis subpreceptoris Monsonis et fratris Raimundi de Erolis.

Bernardi diachoni (signo) signum qui hoc scripsit.

a. Sigue tach. amitum.- b. sigue tach. amitum

Al dorso: Carta corone domini regis (coet). Carta corone, mitre et ceptri domini regis Petri antiqui (final s. XIII). 


\section{RÉSUMÉ}

Les ornements (manteau, dalmatique, couronne, mitre, sceptre et globe) avec lesquelles fut couronné le roi d'Aragon Pierre I-II le Catholique par le pape Innocent III (Rome, 1204) furent déposés dans l'abbaye aragonaise de Sijena. L'année 1218 la prioresse Ozenda reconnait les avoir et les offre au nouveau roi Jacques I.

\section{SUMMARY}

The mantle, dalmatic, crown, mitre, sceptre and globe which the king of Aragon Peter I-II the Catholic was crowned with by the pope Innocentius III (Rome, 1204), were left in deposit in the abbey of Sijena in Aragon. In 1218 the prioress Ozenda recognized the deposit and offered it to the new king James I. 